\title{
Myocardial dysfunction in polymyositis
}

\author{
Mario Sénéchal MD, Martin Crête MD, Christian Couture MD, Paul Poirier MD PhD
}

\section{Sénéchal, M Crête, C Couture, P Poirier. Myocardial dysfunction in polymyositis. Can J Cardiol 2006;22(10):869-871.}

\begin{abstract}
Myocardial involvement in polymyositis is occasionally suspected, but symptomatic cardiac dysfunction is rarely reported. Described in the present report is a 48-year-old woman with a two-year history of polymyositis who suddenly developed near fatal ventricular arrhythmia, and a 56-year-old man with a relapsing polymyositis who developed severe systolic dysfunction. These two cases emphasize the importance of systematic cardiac evaluation when the diagnosis of polymyositis is initially made and the necessity of re-evaluating cardiac function, even in the presence of clinical remission and normalization of creatine phosphokinase with treatment.
\end{abstract}

Key Words: Arrhythmia; Fibrosis; Heart; Polymyositis; Systolic dysfunction

\section{Dysfonction myocardique et polymyosite}

\begin{abstract}
Dans la polymyosite, on soupçonne parfois une atteinte myocardique, mais les cas de dysfonction cardiaque symptomatique sont rares. Le présent rapport décrit le cas d'une femme de 48 ans présentant des antécédents de polymyosite depuis deux ans qui a subitement présenté une arythmie ventriculaire quasi fatale et celui d'un homme de 56 ans victime d'une rechute de sa polymyosite qui a développé une dysfonction systolique sévère. Ces deux cas rappellent l'importance d'une évaluation cardiaque systématique lorsqu'un diagnostic de polymyosite a déjà été posé et la nécessité de réévaluer la fonction cardiaque, même si le patient semble en rémission clinique et même si un traitement a permis de normaliser les taux de créatine phosphokinase.
\end{abstract}

\section{Patient 1}

\section{CASE PRESENTATIONS}

A 48-year old woman first came to the emergency department in October 2001 with complaints of palpitations, dyspnea, progressive muscle weakness, severe gastroesophageal reflux and Raynaud's phenomenon. The patient's vital signs, jugular vein examination and cardiac auscultation were normal. Besides diffuse bilateral crackles on pulmonary auscultation and lower limb weakness, the patient's physical examination was normal. Abnormal laboratory variables were as follows: creatine phosphokinase (CPK) $761 \mathrm{U} / \mathrm{L}, \mathrm{CPK}$ MM 94\%, and CPK MB 6\% (normal value: CPK $195 \mathrm{U} / \mathrm{L}$ or less).

The resting electrocardiogram (ECG) showed normal sinus rhythm, left anterior fascicular block, right bundle branch block, first-degree atrioventricular block and premature ventricular beats (Figure 1). The pulmonary function test demonstrated a slight restrictive pattern with decreased diffusion capacity. The chest $\mathrm{x}$-ray revealed interstitial infiltrates, suggesting fibrosis. Thoracic tomodensitometry confirmed the interstitial infiltrates located predominantly at the pulmonary bases and demonstrated a dilated esophagus. Esophagogastroscopy showed a hiatal hernia, and an upper transit examination showed a loss of peristaltic waves in the distal two-thirds of the esophagus with spontaneous reflux. A $48 \mathrm{~h}$ Holter ECG showed frequent isolated and nonsustained premature atrial complexes and isolated ventricular complexes. At that time, verapamil $120 \mathrm{mg}$ daily was begun; because of Raynaud's phenomenon, beta-blockers were contraindicated and amiodarone was not given because of pulmonary fibrosis. Echocardiography was normal with a left ventricular ejection fraction (EF) of $70 \%$. Polymyositis was proven by muscular biopsy, and a diagnosis of undifferentiated connective tissue disease was made on the basis of the clinical presentation. The patient responded clinically to prednisone and methotrexate. The CPK value normalized to $147 \mathrm{U} / \mathrm{L}$ in August 2002.

However, the patient complained of increased palpitations. Holter monitoring in April 2003 revealed 25,489 isolated premature ventricular complexes, 1999 couplets and 14,303 bigeminal cycles. The patient denied any episode of faintness or syncope. Empirical verapamil was increased to $180 \mathrm{mg}$ daily. Echocardiography was scheduled as an outpatient. She came a few days later for her appointment but suddenly collapsed in the hospital hall. Cardiopulmonary resuscitation manoeuvres were performed for approximately $35 \mathrm{~min}$. The primary arrhythmia documented was ventricular fibrillation. She finally survived with intensive medical treatment and without any neurological deficit. Amiodarone and carvedilol were begun. A few days after her cardiac arrest, echocardiography revealed moderate left ventricular dysfunction with an EF of 35\%. The coronary angiogram was normal. A right ventricular endomyocardial biopsy performed at that time revealed focal interstitial fibrosis as the only positive histological finding (Figure 2). Pertinent negative findings included no evidence of active myocarditis, myocardial ischemia or myocardial hypertrophy. Before leaving the hospital, a defibrillator was installed. The patient did not experience any symptomatic arrhythmia, and

Quebec Heart Institute, Laval Hospital Research Centre, Sainte-Foy, Quebec

Correspondence: Dr Mario Sénéchal, Laval Hospital, 2725 chemin Sainte-Foy, Sainte-Foy, Québec G1V 4G5. Telephone 418-656-8711 ext 4767, fax 418-656-4562, e-mail duboissenechal@videotron.ca

Received for publication March 11, 2005. Accepted August 9, 2005 


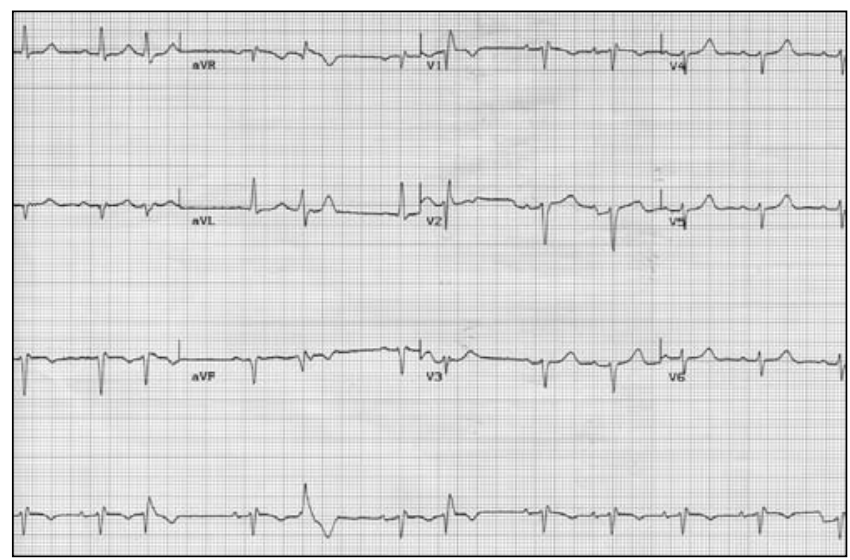

Figure 1) An electrocardiogram showing normal sinus rhythm, left anterior fascicular block, first-degree atrioventricular block, incomplete right bundle branch block and multifocal premature ventricular beats

her clinical evolution was uneventful. One year after her cardiac arrest, her EF remained at 35\%.

\section{Patient 2}

Classical polymyositis was diagnosed and proven by muscular biopsy in a 42-year-old man in January 1989. At the time of diagnosis, isotopic ventriculography revealed an EF of 55\% with normal contractility. The evolution was favourable with methotrexate and prednisone, which was eventually tapered. Between January 1989 and April 2003, no clinical intercurrent flares occurred. Nevertheless, during that period on methotrexate therapy, the CPK values did not normalize, varying between $245 \mathrm{U} / \mathrm{L}$ and $300 \mathrm{U} / \mathrm{L}$ (normal value $195 \mathrm{U} / \mathrm{L}$ or less). In April 2003, the patient (now 56 years of age) complained of progressive muscular weakness. The patient responded clinically to daily prednisone and CPK values normalized five months later. In September 2003, the patient came back to the emergency room complaining of dyspnea and orthopnea. The patient's vital signs were normal. Bibasal crepitations and third heart sound (S3) were found on auscultation. The ECG demonstrated a complete left bundle branch block. Cardiac echocardiography revealed severe systolic dysfunction with an EF of $18 \%$ and diffuse hypokinesis. A cardiac biopsy showed moderate myocardial fibrosis without inflammatory infiltrate, similar findings to our first case. Fosinopril, spironolactone, carvedilol and furosemide were administered at the time of consultation. The patient partially improved, and a biventricular pacemaker was installed in February 2004. Since then, the patient has been in class II failure and his evolution uneventful. After biventricular pacing, the EF improved to 25\%.

\section{DISCUSSION}

We strongly suspect that the increasing number of premature ventricular beats documented in the first case, ultimately leading to a cardiac arrest by ventricular fibrillation, was caused by a progressive myocarditis in the context of an undifferentiated connective tissue disease. To our knowledge, there are no data in the literature about the prevalence and the risk of cardiac abnormalities in the context of undifferentiated connective tissue disease. However, such data exist for specific diseases. In polymyositis or dermatomyositis, cardiac symptoms as the

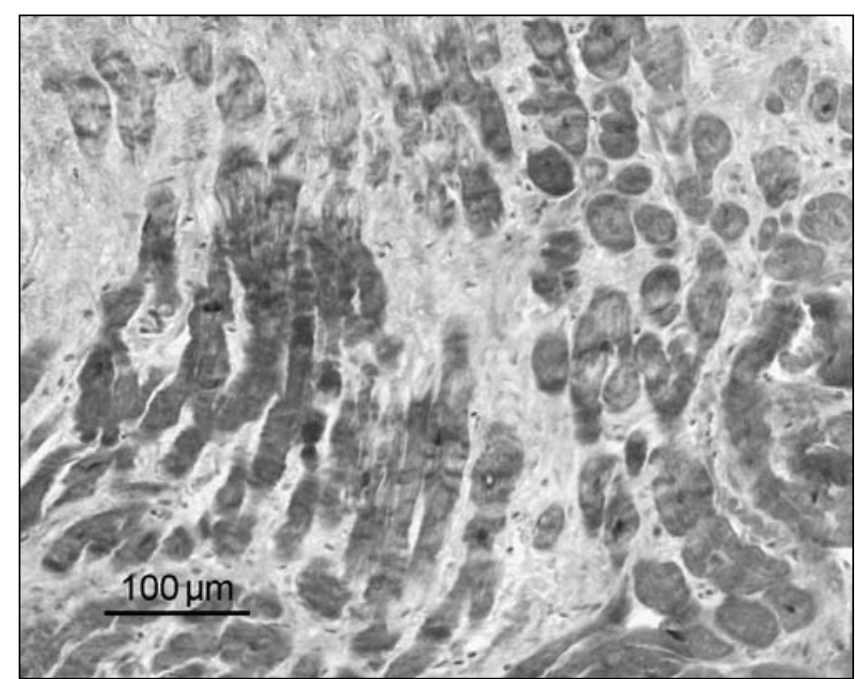

Figure 2) Endomyocardial biopsy showing collagenous fibrosis widening interstitial spaces and normal cardiomyocytes without evidence of myocarditis or myocardial ischemia (Weigert-Masson stain, scale in left lower corner)

presenting complaints are clinically apparent in only $10 \%$ to $15 \%$ of biopsy-proven cases, although functional cardiac abnormalities may be detected by noninvasive means in more than $70 \%$ of patients (1). Previous studies have reported that ECG abnormalities are frequent in polymyositis; however, these changes are frequently minor, and there is no association between these defects and the clinical activity of polymyositis severity, duration of the disease or the degree of CPK elevation (2). In another study, the ambulatory ECG was abnormal in $77 \%$ of cases, most frequently due to premature ventricular beats $(69 \%)$ or brief runs of supraventricular tachycardia (12\%). Palpitations were commonly reported and low-grade, nonsustained ventricular ectopy was frequently encountered (3). A fatal evolution in relation to myocarditis and ventricular dysfunction or high-degree atrioventricular block has also been reported (4). Of note, epicardial arteries are rarely stenotic despite ischemic ECG changes $(5,6)$. However, intramyocardial occlusive small-vessel disease may be present in 20\% of patients at autopsy (7). One retrospective study in four children with systemic sclerosis and myositis reported that a combination therapy constituted of corticosteroids, methotrexate and cyclosporine seemed to be beneficial on muscles, skin and lungs but did not necessarily alter the progression of esophageal or myocardial dysfunction (8).

An interesting study on cardiac and skeletal myopathy in scleroderma reported that $17 \%$ of patients with scleroderma had evidence of myopathy, and found a significantly greater prevalence of myocardial involvement, clinical heart failure and cardiac death in these patients than in patients without myopathy (9). The authors concluded that patients with scleroderma and myopathy are at increased risk of heart failure, sustained symptomatic arrhythmia and cardiac death, particularly sudden death (9). As reported in the first case, one of the main complaints was palpitations. Despite an initial normal cardiac evaluation and favourable general evolution, the patient developed cardiac dysfunction with near-fatal arrhythmia. It is possible that the cardiac muscle suffered active myocarditis between the first symptoms and the normalization of CPK approximately nine months later, following the beginning of 
therapy. It is likely that the myocardial fibrosis found on cardiac biopsy was the final stage of chronic myocarditis in the context of immune disease. Of interest in the second case is that the CPK never normalized in the absence of limb weakness. The evolution toward systolic dysfunction suggests a similar physiopathology. Given the heterogeneous nature of myocardial involvement secondary to myocarditis, the absence of histological myocarditis does not rule out myocarditis, especially when suspected clinically. Sampling errors intrinsic to endomyocardial biopsy may explain the clinicopathological discordance. Furthermore, even at autopsy, myocarditis is demonstrated histologically in only a minority of patients with polymyositis (7).

These cases illustrate our limited knowledge on how and when to investigate the cardiac status of patients with polymyositis. In the presence of cardiac dysfunction, the duration of treatment is uncertain; the ability of CPK normalization to predict favourable cardiac evolution is clearly unknown. Based on favourable clinical evolution combined with normalization of CPK, one cannot assume that the disease is inactive in the heart and that treatment can be safely tapered. These two cases emphasize the importance of cardiac follow-up in patients with polymyositis and the necessity of re-evaluating cardiac function after the initial presentation, even in the presence of clinical remission. We suggest that patients with polymyositis undergo echocardiography to assess cardiac function when the diagnosis is initially made. In the presence of cardiac dysfunction, a right ventricular endomyocardial biopsy may be performed to evaluate the activity of the disease and the degree of fibrosis; in the presence of predominant fibrosis, complete normalization of cardiac systolic function is unlikely. In our opinion, cardiac function should be performed regularly when the medication is tapered.

ACKNOWLEDGEMENT: The authors gratefully acknowledge the valuable help of Michelle Dubois for her technical assistance.

\section{REFERENCES}

1. Gottdiener JS, Sherber HS, Hawley RJ, Engle WK. Cardiac manifestations of polymyositis. Am J Cardiol 1978;41:1141-9.

2. Stern R, Godbold JH, Chess Q, Kagen LJ. ECG abnormalities in polymyositis. Arch Intern Med 1984;144:2185-9.

3. Taylor AJ, Wortham DC, Burge JR, Rogan KM. The heart in polymyositis: A prospective evaluation of 26 patients. Clin Cardiol 1993;16:802-8.

4. Bhan A, Baithun SI, Kopelman P, Swash M. Fatal myocarditis with acute polymyositis in a young adult. Postgrad Med J 1990;66:229-31.

5. Lynch PG. Cardiac involvement in chronic polymyositis. Br Heart J 1971;33:416-9.

6. Lightfoot PR, Bharati S, Lev M. Chronic dermatomyositis with intermittent trifascicular block. Chest 1977;71:413-6.

7. Denbow CE, Lie JT, Tancredi RG, Bunch TW. Cardiac involvement in polymyositis: A clinicopathologic study of 20 autopsied patients. Arthritis Rheum 1979;22:1088-92.

8. Quartier P, Bonnet D, Fournet JC, et al. Severe cardiac involvement in children with systemic sclerosis and myositis. J Rheumatol 2002;29:1767-73.

9. Follansbee WP, Zerbe TR, Medsger TA Jr. Cardiac and skeletal muscle disease in systemic sclerosis (scleroderma): A high risk association. Am Heart J 1993;125:194-203. 